\title{
Pre-earthquake ionospheric anomalies registered by continuous GPS TEC measurements
}

\author{
J. Y. Liu ${ }^{1,2}$, Y. J. Chuo ${ }^{3}$, S. J. Shan ${ }^{1}$, Y. B. Tsai ${ }^{4}$, Y. I. Chen ${ }^{5}$, S. A. Pulinets' ${ }^{6}$, and S. B. Yu ${ }^{7}$ \\ ${ }^{1}$ Institute of Space Science, National Central University, Taiwan \\ ${ }^{2}$ Center for Space and Remote Sensing Research, National Central University, Taiwan \\ ${ }^{3}$ Department of Information Management, Ling-Tung College, Taiwan \\ ${ }^{4}$ Institute of Geophysics, National Central University, Taiwan \\ ${ }^{5}$ Institute of Statistics, National Central University, Taiwan \\ ${ }^{6}$ Institute of Geophysics, National Autonomous University of Mexico, Mexico \\ ${ }^{7}$ Institute of Earth Sciences, Academia Sinica, Taiwan
}

Received: 31 July 2003 - Revised: 10 November 2003 - Accepted: 22 November 2003 - Published: 8 April 2004

\begin{abstract}
In this paper we examine pre-earthquake ionospheric anomalies by the total electron content (TEC) derived from a ground-based receiver of the Global Positioning System (GPS). A 15-day running median of the TEC and the associated inter-quartile range (IQR) are utilized as a reference for identifying abnormal signals during all of the $20 \mathrm{M} \geqq 6.0$ earthquakes in the Taiwan area from September 1999 to December 2002. Results show that the pre-earthquake ionospheric anomalies appear during 18:00-22:00 LT ( $\mathrm{LT}=\mathrm{UT}+8 \mathrm{~h}$ ) within 5 days prior to 16 of the $20 \mathrm{M} \geqq 6.0$ earthquakes. This success rate of $80 \%$ $(=16 / 20 \%)$ suggests that the GPS TEC is useful to register pre-earthquake ionospheric anomalies appearing before large earthquakes.
\end{abstract}

Key words. Ionosphere (ionospheric disturbances; ionosphere-atmosphere interactions)

\section{Introduction}

Many electromagnetic phenomena possibly associated with seismic activities have been extensively discussed in the literature (e.g. Hayakawa and Fujinawa, 1994; Hayakawa, 1999; Hayakawa, 2000; Hayakawa and Molchanov, 2002). Scientists observed anomalies appearing in electron densities of the ionospheric $\mathrm{F}$ region a few days before some strong earthquakes (Pulinets et al., 1994; Pulinets, 1998; Liu et al., 2000). Liu et al. (2000) examined the ionospheric plasma frequency (or electron density) recorded by a local ionosonde and found that the critical frequency of the F2-peak, $f o \mathrm{~F} 2$, significantly decreased a few days prior to most of the $M \geqq 6.0$ earthquakes in the Taiwan area between 1994-1999.

Correspondence to: J. Y. Liu

(jyliu@jupiter.ss.ncu.edu.tw)
Ionosondes have been the most popular instrument probing the ionospheric electron density for more than seven decades (Hunscucker, 1991). Currently, there are more than 200 ionosondes available worldwide. However, only a fraction of them are routinely operational. Therefore, the spatial and temporal coverage of the ionosonde observations are rather limited and difficult to use to correlate with seismic activities systematically. Meanwhile, due to the use of median and high frequencies (MF and HF), 1-20 MHz, ionosondes often suffer from the short wave fadeout and result in data gaps (Davies, 1990). By contrast, today there are thousands of ground-based receivers of the global positioning system (GPS) deployed to monitor the Earth's surface deformation rates (see the papers listed in Calais and Amarjargal, 2000). Owing to the use of two ultra high frequency (UHF, $f_{1}=1575.42 \mathrm{MHz}$ and $f_{2}=1227.60 \mathrm{MHz}$ ) waves, the GPS studies are generally free from the short wave fadeout. Therefore, while performing Earth's surface deformation observations, the same network of GPS receivers can also be used to simultaneously and continuously monitor the ionospheric total electron content (TEC) (for example, see Leick, 1995; Sardon et al., 1994; Liu et al; 1996).

Recently, scientists have found an apparent reduction in GPS TEC a few days prior to some strong earthquakes (selected, e.g. Calais and Minster, 1995; Liu et al. 2001; Liu et al., 2002). However, these articles reported only a limited 1-3 cases. In this paper, we adopt the procedure of Liu et al. (2001) to derive the GPS TEC and then employ the statistical analysis of Liu et al. (2000) to identify possible pre-earthquake ionospheric anomalies 15 days before and after each of the $20 \mathrm{M} \geqq 6.0$ earthquakes in the Taiwan area from September 1999 to December 2002. The features and lead times of the identified pre-earthquake ionospheric TEC anomalies are examined and discussed. 


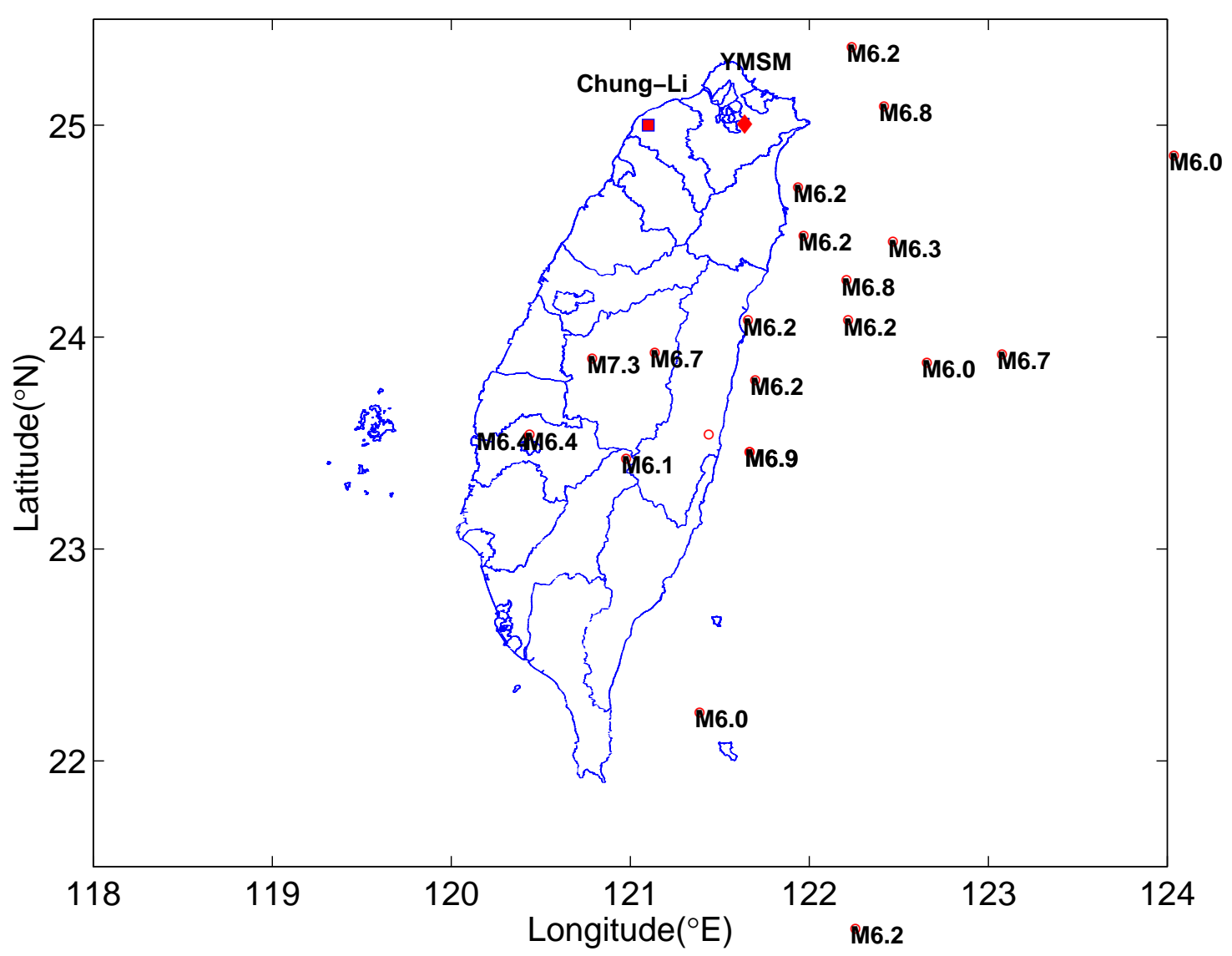

Fig. 1. The locations of the ionosonde, the GPS receiver and the $20 \mathrm{M} \geqq 6.0$ earthquakes in the Taiwan area during September 1999 and December 2002. The square and diamond symbols denote the Chung-Li ionosonde and YMSM GPS receiver, respectively.

Table 1. Catalog of the earthquakes in the Taiwan area used in this study.

\begin{tabular}{ccccccccrrr}
\hline EQK & YY & MM & DD & Hr & Min & Lat. & Long. & Depth & Mag. & P-day (LT) \\
\hline 1 & 1999 & 09 & 21 & 01 & 17 & 23.87 & 120.75 & 1.7 & 7.3 & $-1,-3,-4$ \\
2 & 1999 & 10 & 22 & 10 & 19 & 23.51 & 120.4 & 12.1 & 6.4 & -1 \\
3 & 1999 & 11 & 02 & 01 & 53 & 23.43 & 121.63 & 30.4 & 6.9 & -2 \\
4 & 2000 & 02 & 25 & 14 & 13 & 24.83 & 124.00 & 112 & 6.0 & -2 \\
5 & 2000 & 06 & 11 & 02 & 23 & 23.9 & 121.10 & 10.2 & 6.7 & -3 \\
6 & 2000 & 07 & 16 & 11 & 21 & 20.16 & 122.29 & 10.0 & 7.0 & $-2,-5$ \\
7 & 2000 & 07 & 29 & 04 & 28 & 23.4 & 120.94 & 4.0 & 6.1 & -2 \\
8 & 2000 & 09 & 10 & 16 & 54 & 24.05 & 121.62 & 20.0 & 6.2 & $-1,-2$ \\
9 & 2000 & 12 & 26 & 11 & 20 & 21.18 & 122.22 & 164.2 & 6.2 & $-1,-2$ \\
10 & 2001 & 06 & 13 & 21 & 17 & 24.42 & 122.43 & 54.2 & 6.3 & $\mathrm{X}$ \\
11 & 2001 & 06 & 14 & 10 & 35 & 24.45 & 121.93 & 10.4 & 6.2 & $\mathrm{X}$ \\
12 & 2001 & 11 & 24 & 13 & 46 & 25.34 & 122.20 & 280.4 & 6.2 & -5 \\
13 & 2001 & 12 & 18 & 12 & 02 & 23.89 & 123.04 & 32.2 & 6.7 & -2 \\
14 & 2002 & 02 & 12 & 11 & 27 & 23.77 & 121.66 & 25.1 & 6.2 & $\mathrm{X}$ \\
15 & 2002 & 03 & 31 & 14 & 52 & 24.24 & 122.17 & 9.6 & 6.8 & $-3,-5$ \\
16 & 2002 & 05 & 15 & 11 & 46 & 24.68 & 121.90 & 5.0 & 6.2 & $-3,-4$ \\
17 & 2002 & 05 & 29 & 00 & 45 & 24.05 & 122.18 & 5.7 & 6.2 & $-3,-5$ \\
18 & 2002 & 08 & 29 & 01 & 05 & 22.2 & 121.35 & 13.2 & 6.0 & -2 \\
19 & 2002 & 09 & 01 & 15 & 07 & 23.85 & 122.62 & 35.5 & 6.0 & $\mathrm{X}$ \\
20 & 2002 & 09 & 16 & 08 & 03 & 25.06 & 122.38 & 173.6 & 6.8 & -3 \\
\hline
\end{tabular}



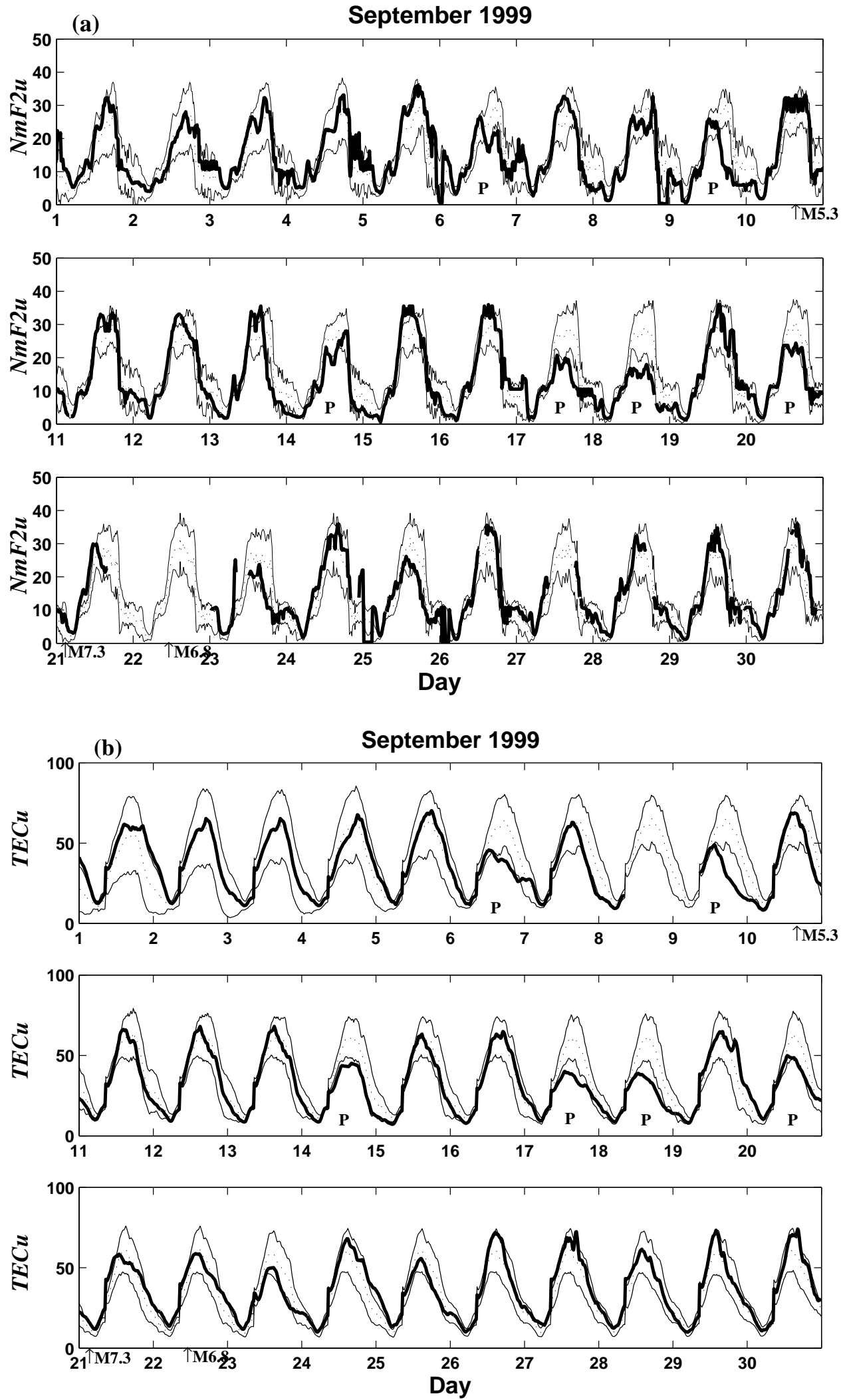

Fig. 2. The variations of $N m \mathrm{~F} 2$ and $V T E C$ observed in September 1999. (a) $N m \mathrm{~F} 2$ and (b) $V T E C$. The bold, dashed, solid curves and the $\mathrm{P}$ character denote the observed $N m \mathrm{~F} 2$ or $V T E C$, associated 15-day medians, upper/lower bounds and detected seismo-ionospheric anomalies, respectively. $1 \mathrm{Nm} \mathrm{F} 2 \mathrm{u}=10^{12} \mathrm{el} / \mathrm{m}^{3}$ and $1 \mathrm{TECu}=10^{16} \mathrm{el} / \mathrm{m}^{2}$. 

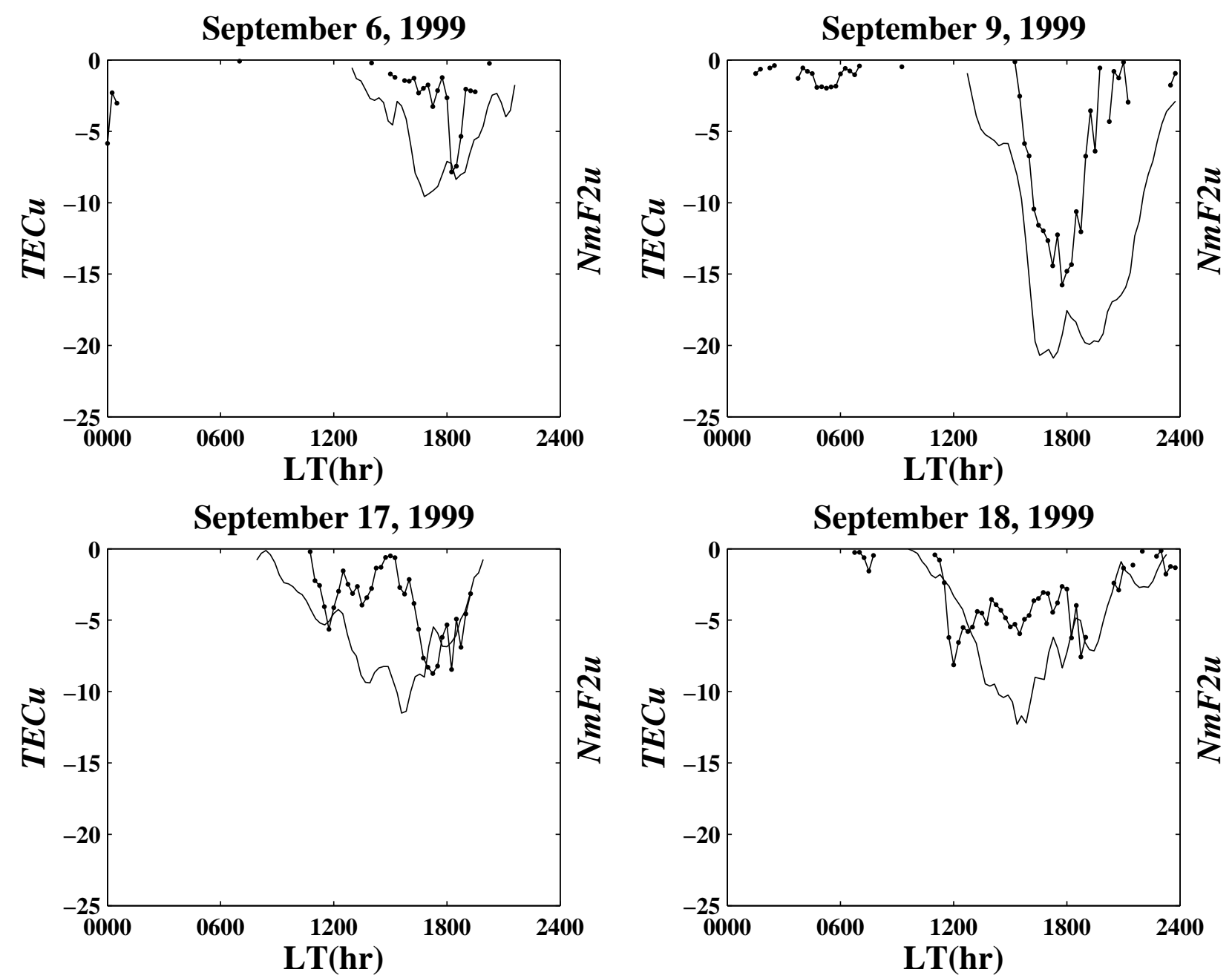

Fig. 3. The strength of four pre-earthquake ionospheric anomalies in $N m \mathrm{~F} 2$ (dotted lines) and $V T E C$ (solid lines) appear on 6, 9, 17 and 18 September 1999. The strength is defined as the departure of the observed quantities from the associated medians.

\section{Observation and methodology}

Owing to being a dispersive medium of the ionosphere, scientists can derive the TEC from the signals recorded by ground-based GPS receivers every 30 s (for example see Sardon et al., 1994; Leick, 1995; Liu et al,; 1996). The slant total electron content, STEC, along ray path $l$ between a GPS satellite, $T x$, and a ground-based receiver, $R x$, can be written as:

$S T E C=\int_{R x}^{T x} N d l=\frac{f^{2}}{40.3} \int_{R x}^{T x}\left(n^{-1}-1\right) d l$

$=\frac{f^{2}}{40.3} \int_{R x}^{T x}\left[\left(\sqrt{\left(1-\frac{f_{N}^{2}}{f^{2}}\right)}\right)^{-1}-1\right] d l$,

where $N$ is the electron density in $\mathrm{el} / \mathrm{m}^{3}, n$ denotes the refractive index, and $f$ and $f_{N}$ represent radio wave and plasma frequency in $\mathrm{Hz}$, respectively. The $l$-axis stands for the receiver-to-satellite direction. From recorded broadcast ephemeris (GPS satellite parameters) and given local subionospheric heights, the $S T E C$ can be converted into the vertical total electron content $V T E C$ at its associated longitude and latitude (Tsai and Liu, 1999). Both STEC and $V T E C$ are in TECu $\left(1 \mathrm{TECu}=10^{16} \mathrm{el} / \mathrm{m}^{2}\right)$.

Taiwan is located in the seismic zones around the rim of the Pacific Ocean and, therefore, earthquakes frequently occur. For instance, the recurrence interval of an $\mathrm{M} \geq 5.0$ earthquake between 1991-1999 is about 13-15 days. To identify abnormal signals, we compute in this paper the median $\tilde{X}$ of the previous 15-day VTECs (or foF2) and the associated inter-quartile range $I Q R$, to construct the upper bound $\tilde{X}+I Q R$ and lower bound $\tilde{X}-I Q R$ at a certain local time (LT). Under the assumption of a normal distribution with mean $\mu$ and standard deviation $\sigma$ for the VTEC (or $f o \mathrm{~F} 2$ ), the expected value of $\tilde{X}$ and IQR are $\mu$ and $1.34 \sigma$, respectively (Klotz and Johnson, 1983). If an observed VT EC (or $f o$ F2) falls out of either the associated lower or upper bound, we declare with a confidence level of about $80-85 \%$ that a lower or upper abnormal signal is detected. 


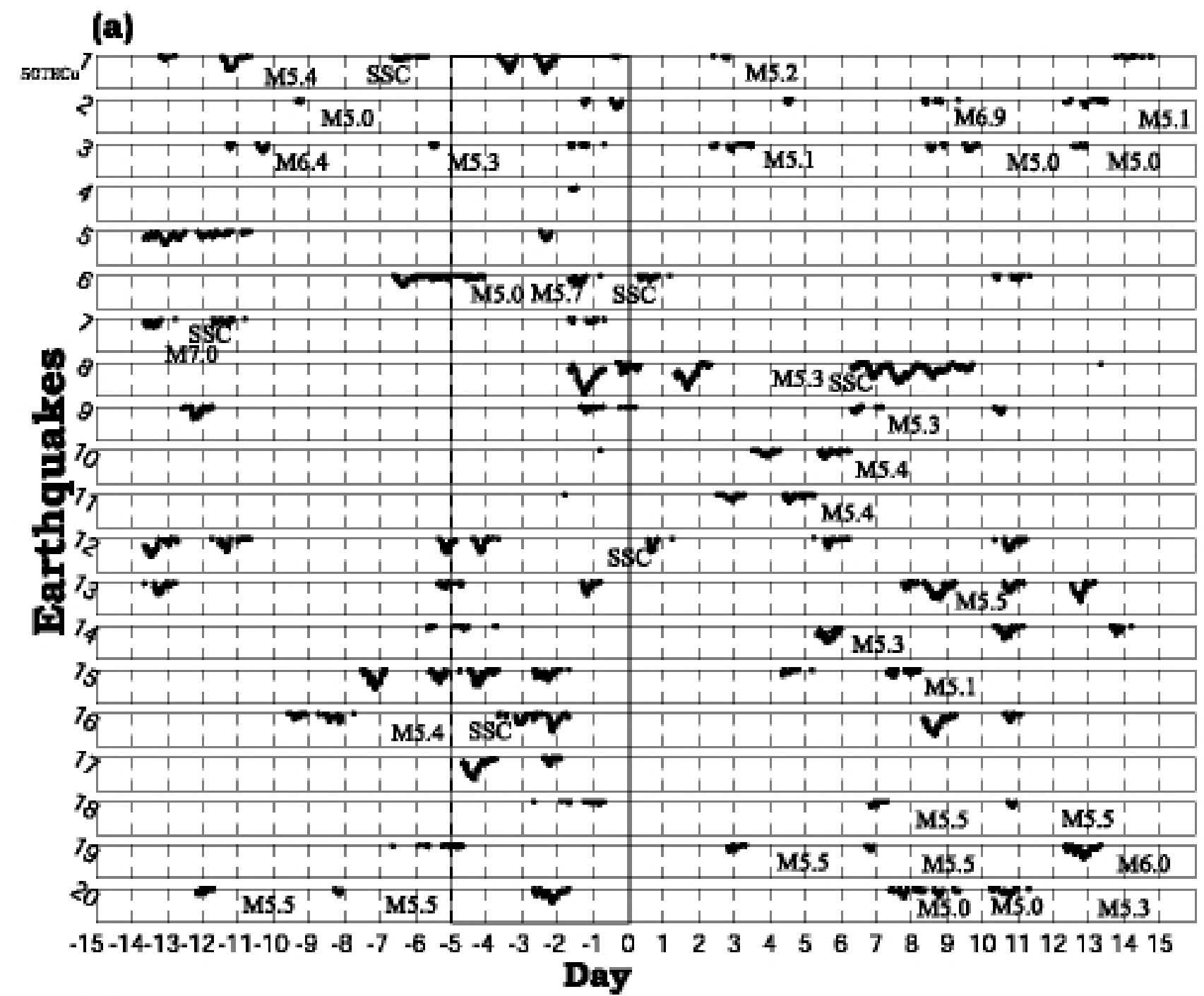

(b)

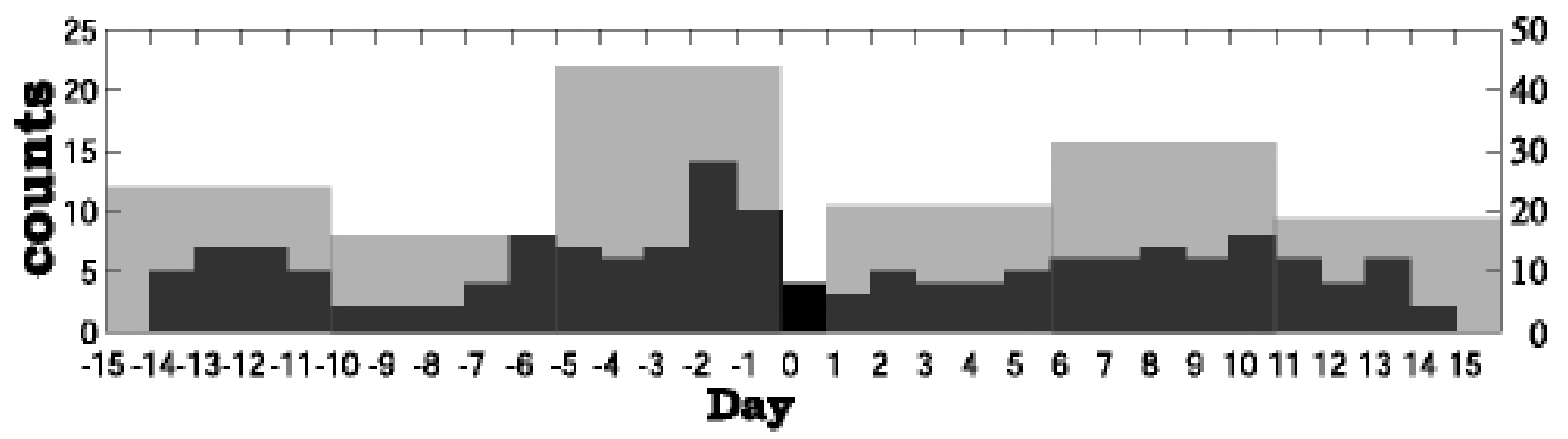

Fig. 4. The lower anomalies that occurred within 15 days before and after the $20 \mathrm{M} \geqq 6.0$ earthquakes. (a) The observed $V T E C$ exceed the associated lower bound. (b) The counts of lower anomalies appear more than $2 \mathrm{~h}$ during 12:00-22:00 LT for each day (dark histogram, left vertical axis) and every 5-day (gray histogram, right vertical axis). The day is in LT. 


\section{(a)}

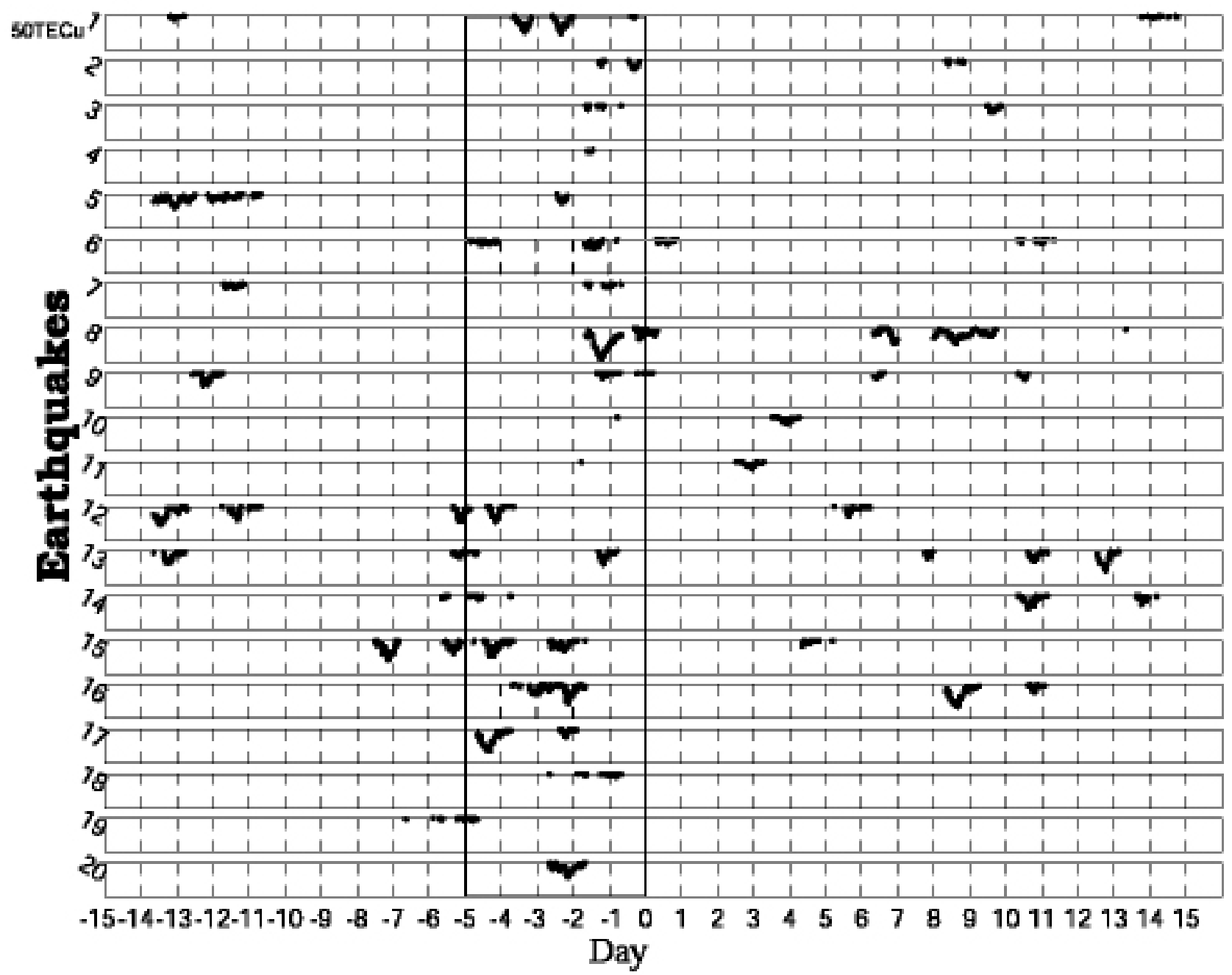

(b)

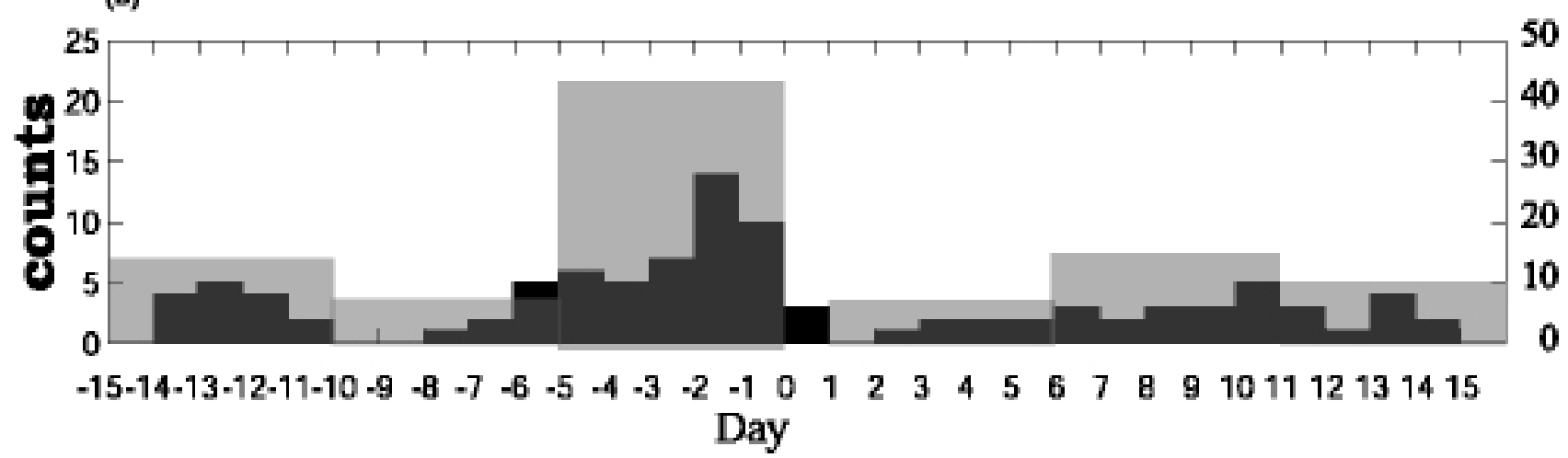

Fig. 5. The same plots as in Fig. 4 but after removing the anomalies related to the M5.0 s earthquakes and the geomagnetic storms. 


\section{Data analysis and interpretation}

Figure 1 illustrates the locations of a local ionosonde at Chung-Li $\left(25^{\circ} \mathrm{N}, 120^{\circ} \mathrm{E}\right)$, a GPS receiver at Yang-Ming San Mountain (YMSM, $25.3^{\circ} \mathrm{N}, 120^{\circ} \mathrm{E}$ ) and the epicenters of all the $20 \mathrm{M} \geqq 6.0$ earthquakes that occurred in the Taiwan area during September 1999 and December 2002. Table 1 gives a catalog of the earthquakes, which summarizes the origin time, epicenter, magnitude and the anomaly day(s) before each earthquake. The M7.3 Chi-Chi earthquake was the strongest one among the 20 earthquakes. To validate the applicability of the GPS TEC, we compare first the temporal variations between the co-located VTEC (right above the Chung-Li ionosonde station) from the YMSM GPS receiver and the F2-peak electron density $N m \mathrm{~F} 2=(f o F 2)^{2} / 80.3$ (for details, see Davies, 1990) from the Chung-Li ionosonde during the month of the Chi-Chi earthquake (see Figs. 2a and b). The bold lines in the figures denote the observed $N m \mathrm{~F} 2$ and $V T E C$, the dashed lines show the associated 15-day medians, and the solid lines represent the upper/lower bounds, respectively. Finally, the $\mathrm{P}$ characters highlight the day when the pre-earthquake ionospheric anomalies are detected. Although local time (LT) and universal time (UT=LT- $8 \mathrm{~h}$ ) are, respectively, used by the ionosonde and the GPS, for simplicity, the LT coordinate is adopted in this study. It is found that both the $N m \mathrm{~F} 2$ and $V T E C$ plots simultaneously reveal strong anomalies on 6, 9, 14, 17 and 18 September, as well as one weak anomaly on 20 September 1999. Those appearing on 17, 18 and 20 September are the pre-earthquake anomalies of the Chi-Chi earthquake. The anomalies on 6 and 9 September are considered to be related to an M5.3 earthquake which occurred on 10 September. Two geomagnetic storm sudden commencements (SSC) occurred on 12 and 22 September 1999 . The anomaly that appeared on 14 September was probably a fluctuation perturbed by the geomagnetic storm on 12 September, since a few hours to two days after a SSC, the ionospheric electron density might significantly decrease (Davies, 1990; Kelley, 1989). Figure 3 shows the strength of the $N m \mathrm{~F} 2$ and $V T E C$ anomalies on 6, 9, 17 and 18 September for the M5.3 and the Chi-Chi earthquakes, respectively. It can be seen that the two quantities have consistent tendencies, which significantly decrease between 12:00 and 22:00 LT. Such consistent tendencies suggest that the TEC data can be employed to search for possible anomalies before $\mathrm{M} \geqq 6.0$ earthquakes. Figure $4 \mathrm{a}$ displays the variations of lower anomalies detected 15 days before and after all the $20 \mathrm{M} \geqq 6.0$ earthquakes during September 1999 and December 2002. To avoid detecting other short lifetime perturbations caused by some other geophysics, such as thunderstorm, traveling ionospheric disturbances, ionospheric bubbles, etc. (Davies, 1990), we consider an anomalous day when observed VTEC s continuously exceed the associated lower bounds for at least $2 \mathrm{~h}$ during 00:00-24:00 LT. There are 106 lower anomalous days detected by this criterion during the entire studied period of $620(=20 *(15+1+15))$ days. This shows that the chance of observing an anomaly during the entire investigated period is about $25 \%(=158 / 620 \%)$.
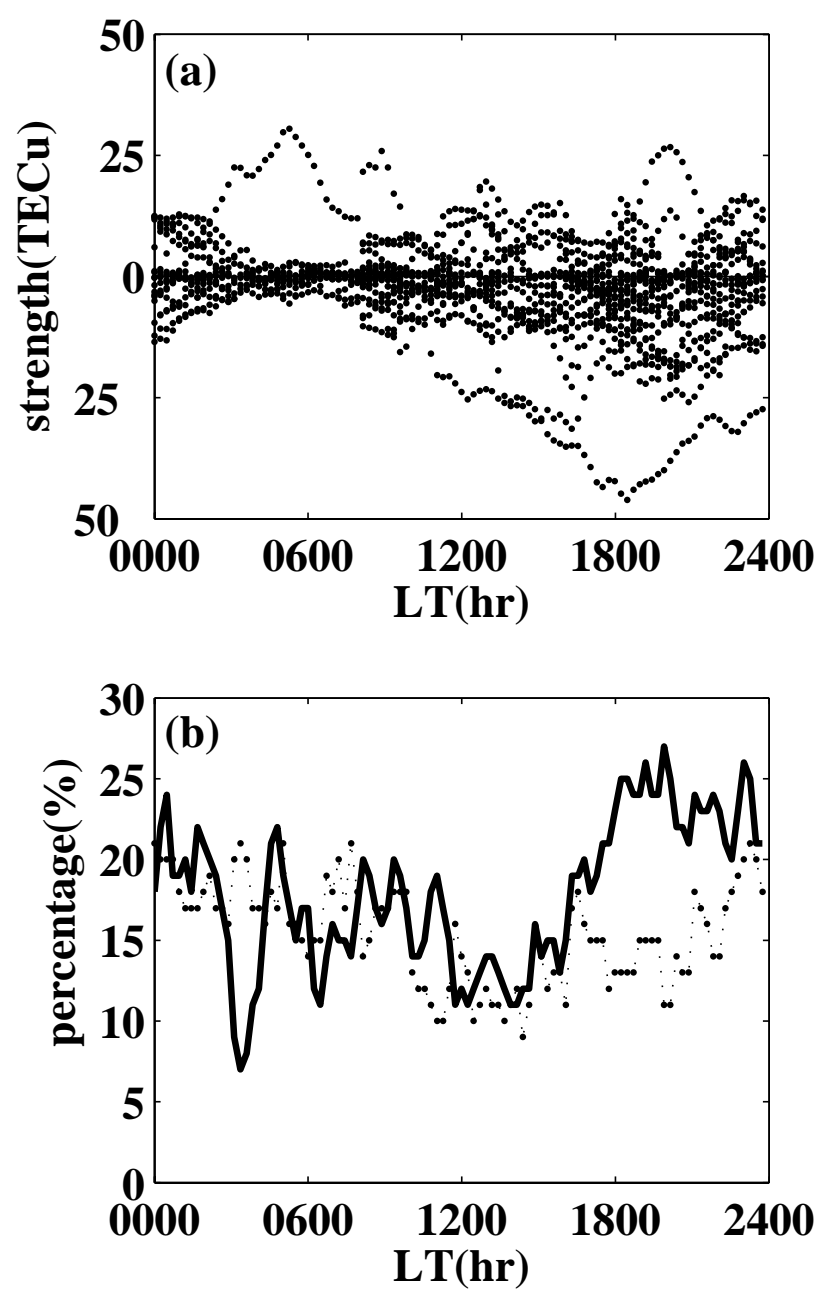

Fig. 6. The strengths and cumulative percentages of the $V T E C$ anomalies appear $1-5$ days before the $20 \mathrm{M} \geqq 6.0$ earthquakes. (a) The upper and lower anomalies strengths. (b) The occurrence percentages of the upper (dotted line) and lower (solid line) anomalies.

Although many $5.0 \leqq M<6.0$ earthquakes and geomagnetic storms (denoted by M5s and SSC in Fig. 4a, respectively) occurred during the study period, Fig. $4 \mathrm{~b}$ shows that the occurrences of the lower anomalous days yield greater counts (8, 6 and 7, respectively) on 1, 2 and 5 days before $M \geqq 6.0$ earthquakes. It can be seen that the occurrence of the lower anomalous 1-5 days prior to the earthquakes is $44 \%$ $(=44 /(5 \times 20) \%)$, which is greater than those of any other 5 day periods (on average about $23 \%$ ) or the entire study period of $25 \%$. To have a better understanding of the relationship between the seismo-ionospheric anomalies and the $\mathrm{M} \geqq 6.0$ earthquakes, we remove the anomalies 1-5 days before the M5.0 s earthquakes and 1-2 days after the SSCs (Davies, 1990; Kelley, 1989). Figure 5a, similar to Fig. 4a, illustrates the appearances of the lower anomalous 15 days before and after the $M \geqq 6.0$ earthquakes, after those anomalies related to the M5.0 s earthquakes and the geomagnetic storms are removed. Figure $5 \mathrm{~b}$ demonstrates that the percentage of the 
lower anomalies $1-5$ days before the $\mathrm{M} \geqq 6.0$ earthquakes is $44 \%$, which is 4 times greater than that of about $11 \%$ on average of any other 5-day periods.

To further understand the pre-earthquake ionospheric TEC anomalies, the strengths and occurrences of the upper and lower anomalies in the VTEC 1-5 days before all the $20 \mathrm{M} \geqq 6.0$ earthquakes are plotted and counted. Figure 6a illustrates that strengths of the anomalies, which is the observed VTECs deviation from the associated medians, enhance during 14:00-22:00 LT, while Fig. 6b shows that cumulative counts of the lower anomalous are clearly greater than those of the associated upper anomalous during 18:00-22:00 LT $1-5$ days before the $M \geqq 6.0$ earthquakes. These suggest the significant lower anomaly appearing 18:00-22:00 LT within 1-5 days before the earthquakes to be the pre-earthquake ionospheric anomalies. Table 1 lists the pre-earthquake ionospheric anomalies that occurred before the $20 \mathrm{M} \geqq 6.0$ earthquakes.

\section{Discussion and conclusion}

It has been shown that both the current VTEC observations and the previous ionosonde $f o \mathrm{~F} 2$ observations of Liu et al. (2000) can simultaneously register the pre-earthquake ionospheric anomalies during the month of the Chi-Chi earthquake occurrence (Figs. 2 and 3). Liu et al. (2001) calculated the correlation coefficient between the co-located $N m \mathrm{~F} 2$ and $V T E C$ 0-7 days prior to the Chi-Chi earthquake to be 0.953 . These agreements suggest that the GPS TEC can be employed to monitor the pre-earthquake ionospheric anomalies. The stack processes for identifying occurrences of the anomalies, as shown in Figs. 4 and 5, demonstrate that the lead time of the VTEC anomalies of the $\mathrm{M} \geqq 6.0$ earthquakes in the Taiwan area is typically $1-5$ days. Table 1 shows that the occurrence rates of earthquakes after the VTEC anomalies within 5 days are $80 \%(=16 / 20)$ which generally agree with the $93 \%$ reported by Liu et al. (2000).

To further understand the features of the pre-earthquake ionospheric anomalies of $V T E C$, we examine the diurnal distributions of strengths and counts of the upper and lower anomalous within $1-5$ days of the $M \geqq 6.0$ earthquakes. Figures $6 \mathrm{a}$ and $\mathrm{b}$ illustrate that the significant strengths and counts of the lower anomalies appear during 18:00-22:00 LT, which is somewhat later than that of 12:00-18:00 LT, as reported previously by Liu et al. (2000). The discrepancies in the diurnal features of the two anomalies may result from the fact that the $V T E C$ and $f o \mathrm{~F} 2$ (or $N m \mathrm{~F} 2$ ) are two different physical quantities. It is noted that the $N m \mathrm{~F} 2$ is the electron density at the F2-peak, about $300-500 \mathrm{~km}$ altitude, while the VTEC is the integration from the ground-based receiver to the GPS satellite orbit at about $20200 \mathrm{~km}$ altitude (also see Eq. 1). Although the $N m \mathrm{~F} 2$ yields the heaviest weight in computing the VTEC, the part above the F2-peak, ranging from 300 (or 500 ) $\mathrm{km}$ to $20200 \mathrm{~km}$, still has more than $70 \%$ contribution for the VTEC. This means that the ionizations in the higher altitudes, i.e. the upper ionosphere and the lower magnetosphere, have to be taken into consideration. Many coupling mechanisms between the lithosphere, atmosphere, and ionosphere, the dirty plasma diffusion, the atmospheric gravity waves, and the vertical electric fields generated during the earthquake preparation periods have been proposed to explain the seismo-ionospheric anomalies (see papers listed in Hayakawa and Fujinawa, 1994; Hayakawa, 1999; Pilipenko et al., 2001; Tanaka et al., 1999; Pulinets et al., 2000; Hayakawa and Molchanov, 2002; Pulinets et al., 2002). Although, the mechanisms are not fully understood, it is reasonable to assume that the anomalies appear first near the Earth's surface and then extend to higher altitudes. Since a large amount of contribution comes from higher altitudes, the appearance of the diurnal VTEC features may be somewhat later than that of the $N m \mathrm{~F} 2$ (or $f o \mathrm{~F} 2$ ).

In conclusion, the pre-earthquake ionospheric anomalies observed in the Taiwan area show that ionospheric TEC remarkably decreased during 18:00-22:00 LT within 1-5 days before the earthquakes. Today, thousands of ground-based GPS receivers are available worldwide. This study provides a new approach and opportunity without any extra cost to search for and validate the existence of possible seismoionospheric anomalies all over the world.

Acknowledgements. The GPS data and the earthquake catalog are obtained from the Ministry of Interior and the Central Weather Bureau of Taiwan, respectively. This research was supported by the Ministry of Education under Grant 91-N-FA07-7-4 for the iSTEP project of the National Central University.

Topical Editor M. Lester thanks D. Ouzounor and S. Uyeda for their help in evaluating this paper.

\section{References}

Calais, E. and Minster, J. B.: GPS detection of ionospheric TEC perturbations following the January 17, 1994, Northridge earthquake, Geophys. Res. Lett., 22, 1045-1048, 1995.

Calais, E. and Amarjargal, S.: New constraints on current deformation in Asia from continuous GPS measurements at Ulan Baatar, Mongolia, Geophys. Res. Lett., 27, 1527-1530, 2000.

Davies, K.: Ionospheric Radio, Peter Peregrinus Ltd, London, 1990.

Hayakawa, M. and Fujinawa, Y.: Electromagnetic Phenomena Relater to Earthquake Predication, Terra Sci. Pub. Co., Tokyo, 1994.

Hayakawa, M.: Atmospheric and Ionospheric Electromagnetic Phenomena with Earthquakes, Terra Sci. Pub. Co., Tokyo, 1999.

Hayakawa, M.: Seismo Electromagnetics, Monograph of International Workshop on Seismo Electromagnetics, Tokyo, 2000.

Hayakawa, M. and Molchanov, O. A.: Seismo Electromagnetics, Lithospheric- Atmospheric- Ionospheric coupling, Terra Sci. Pub. Co., Tokyo, 2002.

Hunscucker, R. D.: Radio Techniques for Probing the Ionosphere, Springer-Verlag Berkin Heidelberg New York, 1991.

Kelly, M. C.: The Earth's Ionosphere, Academic Press, 1989.

Klotz, S. and N. L. Johnson, (Eds.): Encyclopedia of Statistical Sciences, John Wiley and Sons, 1983.

Leick, A.: GPS satellite surveying, John Wiley, New York, 560 pp, 1995. 
Liu, J. Y., Tsai, H. F., and Jung, T. K.: Total electron content obtained by using the global positioning system, Terr. Atmos. Oceanic Sci., 7, 107-117, 1996.

Liu, J. Y., Chen, Y. I., Pulinets, S. A., Tsai, Y. B., and Chuo, Y. J.: Seismo-ionospheric signatures prior to $\mathrm{M} \geqq 6.0$ Taiwan earthquakes, Geophys. Res. Lett., 27, 3113-3116, 2000.

Liu, J. Y., Chen, Y. I., Chuo, Y. J., and Tsai, H. F.: Variations of ionospheric total electron content during the Chi-Chi earthquake, Geophys. Res. Lett., 28, 1383-1386, 2001.

Liu, J. Y., Chuo, Y. J., Pulinets, S. A., Tsai, H. F., and Zeng, X. P.: A study on the TEC perturbations prior to the Rei-Li, Chi-Chi and Chia-Yi earthquakes, Seismo Electromagnetics: LithosphereAtmosphere-Ionosphere Coupling, edited by Hayakawa, M. and Molchanov, O. A., TERRAPUB, Tokyo, 297-301, 2002.

Pilipenko, V., Shamilov, S., Uyeda, S., and Tanaka, H.: Possible mechanism of the over-horizon reception of FM radio waves during earthquake preparation period, Proc. Japan Academy, 77, Ser. B, 125-130, 2001.

Pulinets, S. A., Legen'ka, A. D., and Alekeseev, V. A.: Preearthquake ionospheric effects and their possible mechanisms, in Dusty and Dirty Plasmas, Noise and Chaos in Spac and in Laboratory, Plenum Publishing, New York, 545-557, 1994.
Pulinets, S. A.: Seismic activity as a source of the ionospheric variability, Adv. Space Res., 22, 6, 903-906, 1998.

Pulinets, S. A., Boyarchuk, K. A., Hegai, V. V., Kim, V. P., and Lomonosov, A. M.: Quasielectrostatic Model of AtmosphereThermosphere-Ionosphere Coupling, Adv. Space Res., 26, 8, 1209-1218, 2000.

Pulinets, S. A., Boyarchuk, K. A., Hegai, V. V., and Karelin, A. V.: Conception and model of seismo-ionospheremagnetosphere coupling, in Seismo- Electromagnetics: Lithosphere-Atmosphere-Ionosphere Coupling, edited by Hayakawa, M. and Molchanov, O. A., TERRAPUB, Tokyo, pp. 353-361, 2002.

Sardon, E., Rius, A., and Zarraoa, N.: Estimation of the transmitter and receiver differential biases and the ionospheric total electron content from global positioning system observations, Radio Sci., 29, 577-586, 1994.

Tanaka, H., Kamogawa, M., and Ohtsuki, Y.: The interation between bulk plasmas and electromagnetic waves assisted by surface roughness, Proc. Japan Academy, 75, Ser. B, 190-194, 1999.

Tsai, H. F., and Liu, J. Y.: Ionospheric total electron content response to solar eclipses, J. Geophys. Res., 104, 12 657-12 668, 1999. 